\title{
"Práticas de pensamento" e o debate curricular: contribuições a partir de Foucault-Cortázar
}

\author{
Cintya Regina Ribeiro*
}

\section{Resumo}

No âmbito educacional, questões relativas aos fundamentos e aos processos de conhecimento têm sido historicamente discutidas no campo do currículo. 0 artigo visa discutir essa centralidade da questão do conhecer, propondo um deslocamento da problematização do conhecimento para a do pensamento. Para tal, propõe a problematização do estatuto do conhecer por meio de investigações de "práticas de pensamento". Metodologicamente, o estudo constrói um território de exterioridade tensionado entre educação, filosofia e literatura. A partir da filosofia, resgata o pensamento de Michel Foucault; a partir da literatura, focaliza o escritor Julio Cortázar. Alinhada às vertentes de crítica da linguagem, a análise aponta contribuições para o debate educacional, propondo outras hipóteses de trabalho de pesquisa curricular, ancoradas na necessidade ético-política de produzir genealogias de práticas de pensamento. Conclui, por meio da articulação Foucault-Cortázar, sobre a necessidade de problematização das práticas de pensamento no interior de nossos próprios campos de pesquisa.

\section{Palavras-chave}

Práticas de pensamento, Michel Foucault, Julio Cortázar, pesquisa curricular, genealogia.

* Faculdade de Educação, Universidade de São Paulo (USP), São Paulo, São Paulo, Brasil. cintyaribeiro@usp.br 


\title{
"Practices of Thought" and Curricular Debate: Contributions from Foucault-Cortázar
}

\begin{abstract}
In education, issues related to knowledge processes have historically been discussed by curriculum studies. The article aims to discuss the question of knowing, through an investigation of the "practices of thought". Methodologically, the study builds a territory of exteriority stretched among education, philosophy (Michel Foucault) and literature (Julio Cortázar). The analysis aims to contribute to the educational debate by proposing working hypotheses for curriculum research anchored in the ethical-political need of producing genealogies of "practices of thought". It concludes, by articulating Foucault-Cortázar, to discuss the need of questioning the practices of thought in our own research areas.
\end{abstract}

Keywords Practices of thought, Michel Foucault, Julio Cortázar, curriculum studies, genealogy. 
Questões relativas aos fundamentos e aos processos de conhecimento, ao serem abordadas no âmbito educacional, têm sido historicamente articuladas às discussões no campo do currículo (Silva, 2002a). Pretendemos discutir essa centralidade da questão do conhecer, propondo um deslocamento da problematização do conhecimento para a do pensamento, tanto na área educacional, de modo geral, quanto no domínio curricular, especificamente.

Argumentamos no sentido de que o ato de conhecer demanda ser discutido a partir de uma problematização da experiência de pensamento. Em se tratando de matizar modos de pensar, atentando para os efeitos intensivos de suas variações, propomos o conceito de "práticas de pensamento". Tal formulação justifica-se pela necessidade analítica de recusa das formas canônicas do ato de conhecer a fim de abarcar os jogos linguísticos de pensamento em sua multiplicidade. Afirmamos que estes não tendem a restringir-se aos clássicos movimentos de representação, uma vez que também podem provocar fluxos de diferenciação e criação.

A problematização das práticas de pensamento atuaria em duas frentes articuladas: a) no estabelecimento de uma crítica ao procedimento linguístico da representação - baliza que tem configurado “o que é o pensar”, particularmente na seara educacional. Vale pontuar que o princípio da representação tem consolidado funcionalidades sociais ao gesto de pensar, produzindo atos de interpretação, reflexividade, (re)conhecimento, (re)cognição; b) na exploração de movimentos disruptivos diante de tal ordenação representacional, visando forjar experiências de diferenciação no próprio ato de pensar. Afirmamos que tais movimentos inauguram outra modalidade de crítica, em relação tanto ao horizonte das políticas e das práticas curriculares quanto ao das práticas de pesquisa curricular.

Metodologicamente, a pesquisa desenvolve-se a partir de um território tensionado entre os saberes da filosofia, da literatura e da educação. Tal esforço ancora-se na hipótese de Michel Foucault de que o pensamento - abordado como experiência de diferenciação e não como reflexividade ou (re)conhecimento - emerge a partir de uma relação agonística com sua própria exterioridade: daí a ideia de um "pensamento do fora" ou "pensamento do exterior" - discussão empreendida por Foucault a partir da obra de Maurice Blanchot (Foucault, 2001; Levy, 2003).

Necessário demarcar que "o fora” ou a exterioridade não supõem uma oposição interior/exterior, "porque é o exterior do interior” (Revel, 2011, p. 32, grifo nosso). Informe, a exterioridade não forja um lugar para além das relações de poder, mas 
remete a uma qualidade intensiva da experiência, referindo-se a um movimento de “dobra" que se faz do/no próprio interior da linguagem, num esforço agonístico de resistência/criação (Deleuze, 1988).

Conduzimos o estudo a partir da exploração desse efeito de exterioridade do pensamento disparado pela tensão entre o debate curricular contemporâneo acerca do conhecimento, certas problematizações suscitadas a partir do pensador Michel Foucault e de alguns elementos da linguagem literária do escritor argentino Julio Cortázar. De Foucault, destacamos a condição agonística do pensamento, abordando-o como uma atitude crítica peculiar, tomada como acontecimento ou como experiência ético-política; de Cortázar, enfatizamos mecanismos estratégicos de sua linguagem literária que incitam à radicalidade de experiências de pensamento, afirmando, de forma trágica, o esgotamento de nossos modos canônicos de pensar.

Tendo em vista acionar pensadores/problemas exteriores ao campo da educação num mesmo circuito discursivo - qual seja, o de uma problematização das práticas de pensamento no horizonte educacional-curricular -, lancemo-nos ao encontro com as intensas experiências de pensamento desses autores.

\section{A condição agonística do pensamento: um efeito Foucault no debate curricular}

$\mathrm{Na}$ análise do pensamento de Gilles Deleuze em Theatrum Philosophicum, Foucault (2005c, p. 242-243, grifos do autor), ao problematizar a filosofia na atualidade, provoca:

qualquer verdadeiro problema deve ter uma solução, pois pertencemos a escola de um mestre que só pergunta a partir das respostas inteiramente escritas em seu caderno, o mundo é nossa sala de aula. Ínfimas crenças... Mas quais? A tirania de uma vontade boa, a obrigação de pensar "em comum" com os outros, o domínio do modelo pedagógico e, sobretudo a exclusão da tolice, eis toda vilania moral do pensamento, da qual seria fácil, sem dúvida decifrar o jogo em nossa sociedade. É preciso nos libertarmos disso.

Implicada na verve nietzschiana, a ironia foucaultiana aponta que o conhecimentoesse conjunto de relações linguísticas entre homens e mundo - tem se configurado, no Ocidente, como um exercício de trucagens nos jogos de perguntas e respostas, 
com seus efeitos de previsibilidade e aplicabilidade. 0 paralelismo com o modo operativo da escola - o mundo como sala de aula, passível de ser circunscrito no caderno do mestre - é expressão de uma forma de vida orientada pela vontade de poder apropriação e domínio do mundo.

A eficácia desse “modelo escolar” parece ser proporcional à despotencialização das experiências de pensamento, uma vez que, nessa chave pedagogizante, estas tenderiam a constituir-se como práticas de reflexividade voltadas ao (re)conhecimento e à (re)cognição, tornando-se mais refratárias às possibilidades de diferenciação e criação de pensamento.

Recusando tanto a condição soberana do sujeito da razão como lócus ontológico do pensar quanto o estatuto do conhecimento como baliza da verdade, a investida foucaultiana abala valores prevalecentes nas formas contemporâneas de vida, na medida mesma em que coloca em cena o caráter histórico-cultural e, portanto, dessubjetivado do próprio ato de pensamento.

As incisões realizadas por Foucault sugerem a suspensão de certas verdades no âmbito das práticas educacionais, engendrando questões irrevogáveis para os pesquisadores em educação.

Nos rastros das problemáticas trazidas por Nietzsche acerca da verdade - questão motriz no pensamento de Foucault $(1999,2005$ a) -, os pesquisadores educacionais Corazza e Tadeu (2003, p. 37-38, grifos dos autores) afirmam:

0 componente mais óbvio de uma teoria do currículo tem a ver com a questão do conhecimento e da verdade. Afinal, supõe-se que a questão central da teorização curricular é "o que deve ser ensinado?", o que, por sua vez, remete à questão mais ampla "o que constitui conhecimento válido ou verdadeiro?" [...] Todo currículo "quer" modificar alguma coisa em alguém, o que supõe, por sua vez, alguma concepção do que é esse "alguém" que deve ser modificado. [...] Ou seja, todo currículo carrega, implicitamente, alguma noção de subjetividade e de sujeito.

Desdobrada da racionalidade moderna, a ordem discursiva curricular tem se fundado em dois pilares: a verdade do sujeito do conhecimento, transposto como sujeito da educação (sujeito crítico-reflexivo e sujeito afetivo-cognitivo); a verdade da razão, como fundadora da verdade do ato de conhecer. Alinhando seu estudo à vertente 
pós-estruturalista, Corazza e Tadeu (2003) destacam a necessidade de problematizar a economia de valores que postula tais verdades. Uma vez que estas são efeitos dos jogos de poder e valoração, atestam, antes, o caráter construcionista e ficcional das realidades delas decorrentes. Evocar a dimensão representacional e, portanto, interpretativa e perspectivada de premissas pedagógicas naturalizadas parece ser o desafio proposto pelos autores.

Essa suposta ontologia do sujeito e do ato de conhecer remete a práticas de pensamento fundadas na reflexividade da razão. Nesse caso, o ato de pensar reduz-se a exercício de validação representacional - mera estratégia linguística de reforço de operações de (re)conhecimento e (re)cognição. Pensar, aqui, se confundiria com as clássicas formas de conhecer, revalidando processos linguísticos de decodificação e recodificação de senhas culturais. A eficácia do mecanismo parece residir no efeito circular e de retroalimentação dessas operações. Disso deriva a perspectiva de que caberia à educação escolar a competente gestão cognitiva dos sujeitos pedagógicos. Daí o efeito Foucault no debate curricular: o alerta diante das práticas de pensamento trucadas do modelo escolar.

Implicados na crítica radical às práticas de pensamento no cerne do debate curricular, objetivamos problematizar esse caráter representacional do conhecimento, de modo a ensaiar possibilidades de abordagem do pensar como uma potência informe de diferenciação.

Para tal incursão, sigamos as pistas foucaultianas: o problema do pensamento não remete a uma chave epistemológica ou cognitiva; configura-se como prática discursiva e, portanto, constitui alvo de uma problematização ético-política. Tal investida requer abdicar do princípio da razão como substancialização da condição humana, colocando em causa a imagem do pensamento como uma operação reflexiva inata a um sujeito da razão.

Essa analítica recusa a abordagem do pensamento como atributo inerente a um pretenso sujeito da razão e toma-o como efeito de jogos de verdade - esse campo de relações de poder no qual os saberes disputam a afirmação da "verdade".

Da radicalidade dessas proposições deriva uma questão medular na obra foucaultiana: a discussão das condições de emergência de uma singular atitude crítica ou de um pensamento crítico, ou melhor, de uma experiência de pensamento como prática afirmativa de liberdade (Foucault, 2004a).

Ao discutir o clássico texto, $O$ que é o esclarecimento? - escrito por Immanuel 
Kant, em 1784 -, Foucault $(2000,2005$ b, 2010) entrevê um vetor diferencial que parece mobilizar o gesto público do filósofo prussiano em seu ato de escrita - a abordagem da problemática moderna do governo e da liberdade, sobretudo, diante do próprio ato de pensar.

Foucault (2000) analisa que a questão de como governar tem se apresentado como um problema recorrente desde os séculos XV e XVI, tendo encontrado, no século XVIII, a partir do horizonte das Luzes, novo desafio - ético-político - que remeteria à questão da medida, dos limites dos atos de governar.

Vou dizer que em torno dessa grande inquietude relativa às maneiras de governar, na procura de maneiras de governar pode-se relevar uma questão permanente: “Como não ser governado desse modo, em nome desses princípios, em vista de tais objetivos e por meio de tais procedimentos, não desse modo, não para isto, não por estas pessoas". (Foucault, 2000, p. 171, grifos do autor)

Esse problema sobre os limites daquilo que nomeia como governamentalização da vida - essa "relação do governo de si com o governo dos outros" (Foucault, 2010, p. 8) - parece encontrar formulação no âmago desta pergunta extraordinária que Kant persegue em seu texto jornalístico: “O que é a atualidade?”. Tal indagação inauguraria um movimento singular na própria atualidade da filosofia: deslocando a clássica questão sobre a verdade, uma interrogação filosófica a respeito da atualidade coloca em cena o dilema do homem perante o agir em seu próprio tempo.

Essa discussão é nuclear para situarmos uma abordagem outra acerca do pensamento, ou do pensamento como experiência de diferenciação. Para Foucault (2010), Kant teria aberto duas linhagens de crítica: a) uma entendida como analítica da verdade, ou seja, uma investigação sobre as condições de possibilidade para a constituição do conhecimento verdadeiro; b) outra experienciada como ethos, isto é, uma atitude necessária de pensamento, por parte de um sujeito histórico, marcada pelo uso público da razão.

Foucault resume a distinção: uma filosofia crítica, fundada na analítica da verdade; um pensamento crítico qualificado como uma ontologia histórica do presente e de nós mesmos. É nessa segunda vertente que o pensador francês se inscreve.

“Qual é o campo atual de nossas experiências? Qual é o campo atual das expe- 
riências possíveis?” (Foucault, 2010, p. 21). Eis as questões desdobradas acerca da atualidade a partir dessa forma outra de pensamento, a qual não teria como motor a clássica busca de adequação com uma suposta verdade legitimada; ao contrário, sua força provém da inquietação ético-política diante dos limites dos atos de governar, seja em relação a si mesmo ou aos outros.

Seguindo essas pistas, o diferencial que irrompe do empreendimento kantiano parece manifestar-se no próprio ato interrogativo conduzido pelo uso público da razão na arena de seu próprio tempo. Essa corajosa presentificação do gesto inquiridor, impregnado de problematização histórica, configura-se como um acontecimento. A ideia de acontecimento é salutar para conferir o selo de distinção dessa perspectiva crítica: o acontecimento é refratário a quaisquer tentativas de ordenamento histórico, de previsibilidade, de controle. Apresenta-se como uma espécie de dobra temporal; emerge a partir de uma tomada de distância do magma absorvente do tempo, para instalar-se/afirmar-se como uma força de ultrapassagem desse mesmo tempo; ou, dito de outro modo, para introduzir a diferença.

Quanto a esse aspecto, Foucault (2005b, p. 337) esclarece que Kant "não busca compreender o presente a partir de uma totalidade ou de uma realização futura. Ele busca uma diferença: qual a diferença que ele introduz hoje em relação a ontem?" Tal abordagem instiga nossas questões educacionais relativas às práticas de pensamento. Pensar poderia remeter à experiência do acontecimento - uma experiência da diferença: ato incisivo de verticalização, de corte do discurso; ruptura fulcral do tempo presente, abrindo-o ao imponderável de suas possibilidades.

Inegavelmente, trata-se de um gesto ético-político, pois os atos de pensar acionam simultaneamente formas de subjetividades e de vidas sociais, implicando modos de relação consigo e com os outros. No limite, essa discussão busca problematizar as práticas de pensamento vigentes num certo corte histórico, de maneira que também o sujeito pensante seja colocado sub judice em sua condição de porta-voz da verdade.

Assim, a crítica, como uma atitude geral do pensamento (Foucault, 2000), constitui-se como um "êthos, uma via filosófica em que a crítica do que somos é simultaneamente análise histórica dos limites que nos são colocados e prova de sua ultrapassagem possível” (Foucault, 2005b, p. 351).

Daí Deleuze (1992, p. 128, grifos do autor) afirmar que "pensar torna-se, como diz Foucault, um ‘ato arriscado', uma violência que se exerce primeiro sobre si mesmo”. 
Na exploração dessa dobradiça histórica que articula sujeito e verdade/ conhecimento, abrir-se-ia a possibilidade de interrogar o pensamento, ou seja, “liberar o pensamento daquilo que ele pensa silenciosamente, e permitir-lhe pensar diferentemente" (Foucault, 1998, p. 14).

Essa modalidade de pensamento Foucault (2004b) qualifica como problematização: atitude que busca investigar de que modo alguma coisa entra no jogo do verdadeiro e do falso e se torna objeto do pensar. Problematizar requer uma investida histórico-genealógica diante do próprio pensamento, como condição do agir crítico.

Judith Revel (2004, p. 82) esclarece que uma “história do pensamento se interessa pela maneira com que se constituem problemas para o pensamento e pelas estratégias que são desenvolvidas para lhes dar resposta". Assim, tomar os modos de pensamento em seu movimento genealógico nos permite tocar a raiz do problema - a implicação entre linguagem e poder ou, precisamente, entre pensamento, política e ética.

Esse outro modo de pensar seria perpassado por uma força inédita: a variável da temporalidade dada pelo critério da "atualidade", ou seja, pelo pulsar do gesto interrogativo diante do próprio tempo contemporâneo desse homem que (se) interroga. Eis, então, o pensamento tomado como experiência e não como interpretação.

Tal ato de perguntar e perturbar o sono do tempo com um corte vertical qualifica, para Foucault, a atitude do pensamento crítico capaz de abrir o próprio tempo à sua diferenciação e ao seu devir. Tendo em vista acionar modos outros de experiência de pensamento, propomos o atravessamento discursivo de outra linguagem - o pensamento literário de Julio Cortázar. A intenção é inventar uma espécie de espaço analítico do "fora" que, por articular provocações da filosofia e da literatura - dois campos exteriores à educação - poderia nos lançar a uma experiência de exterioridade e diferenciação em relação ao nosso próprio pensamento educacional-curricular.

\section{Experiências de pensamento no encontro com a linguagem Cortázar}

Parte da crítica literária tem associado a literatura de Cortázar ao universo fantástico. No intuito de precisar essa conceituação e, ao mesmo tempo, distanciar-se de tais categorizações, o escritor explica: “O fantástico pode acontecer sem que haja uma mudança espetacular das coisas. [...] É uma coisa muito simples, que pode acontecer em plena realidade cotidiana, neste meio-dia ensolarado, agora, entre você e eu" (Cortázar apud Bermejo, 2002, p. 37). 
A relevância da produção desse autor deve-se, aqui, exatamente a esta peculiaridade: o modo como seu texto literário flagra, dilata e satura essa espécie de "vão" entre o cotidiano e o tempo extraordinário que dele irrompe.

Nesta análise, partimos da hipótese de que um gesto interrogativo parece engendrar e percorrer cada narrativa. Tal gesto não se refere ao sujeito-escritor; trata-se de um ato da própria linguagem que, na singularidade de seus procedimentos literários, parece formular perguntas e criar seu modo próprio de colocá-las em circulação.

No intuito de adentrar esses jogos de pensamento, do ponto de vista metodológico, selecionamos três produções literárias do escritor argentino: os contos "A ilha ao meio dia”, "A saúde dos doentes" e "Aí, mas onde, como".

0 primeiro deles narra a situação de um comissário de bordo entregue à contemplação de uma determinada ilha, a qual sobrevoava regularmente por ocasião de seu trabalho.

Nada disso fazia sentido, voar três vezes por semana ao meio-dia sobre Xiros era tão irreal como sonhar três vezes por semana que voava ao meio-dia sobre Xiros. Tudo era falso na visão inútil e repetida; salvo, talvez, o desejo de repeti-la, a consulta ao relógio de pulso antes do meio-dia. (Cortázar, 2009, p. 125)

Cedendo ao encantamento dessas visões, ele projeta viver na ilha. Quando se torna seu habitante, passa a observar, da ilha, o mesmo avião que a sobrevoava: "Fechando os olhos pensou em não olhar para o avião; não se deixaria contaminar pelo pior de si mesmo que uma vez mais ia passar em cima da ilha” (Cortázar, 2009, p.131).

0 relato segue tensionado entre a ordem linear dos eventos e o tênue fio de estranhamento e desconcerto que a desarranja, implacavelmente. No final, o avião cai no mar e o personagem avança para tentar salvar, sem sucesso, o único sobrevivente que surge em meio à água. Os habitantes da ilha contemplam o final da situação: um único corpo estendido na areia.

Cortázar conduz a narrativa de modo supostamente linear, mas, todo o tempo, algo a invade, transtornando-a progressivamente. Somente no final do texto, algo sela esse movimento crescente e, ao mesmo tempo, fulgura, ultrapassando quaisquer expectativas de compreensão - trata-se do mesmo homem, todo o tempo, duplicado nesse trágico e extraordinário vão de vida entre o céu e a ilha. 
Tomemos como um pretenso ato interrogativo dessa linguagem a questão da impotente aderência entre subjetividade e pensamento, e, consequentemente, da necessária morte de si. Lenta e incisivamente, ao mesmo tempo em que o leitor é convocado a apostar no sujeito da liberdade, também vê se corromper esse campo de possibilidades. A linguagem trama a captura que esse mesmo sujeito vai armando contra si, à medida que investe num modo de pensamento/vida fundado na busca de coesão identitária.

Para abordar a falência desse modo de pensamento, o escritor lança mão de um recurso de radicalização da experiência, levando ao limite, no mecanismo da própria linguagem, a empreitada do personagem. Nesse ato, estrangula, por fim, tanto o sujeito da busca quanto o modo de pensamento que o produz.

No conto, o sujeito-personagem não se salva, mas, ao erigir os lentos caminhos de sua morte, travestidos de liberdade, arremessa essa mesma morte à estupefação do leitor. Esse arremesso não se faz por metáforas, pois o efeito impactante não advém da ordem dos sentidos e da significação. É o próprio funcionamento dessa linguagem-Cortázar, com seu corte seco, que nos abandona à própria sorte, ao final desse beco, estrategicamente, sem saídas presumíveis.

A possibilidade de experiência de pensamento nasce dessa experiência linguística de morte. Aquilo que aniquila o personagem não é a opção por esta ou outra forma identitária, mas a própria premissa de que haveria uma identidade a ser buscada como resguardo de liberdade. A impossibilidade de escapar desse pensamento biunívoco levou ao embotamento de outros modos de pensar e do próprio viver.

É no gesto de leitura que se faz a superfície mesma de experiência de embotamento de um modo de pensamento. Cortázar não fala sobre isso numa chave temática, mas faz isso acontecer no próprio mecanismo da linguagem literária, quando o leitor é laçado no pacto narrativo; quando é assombrado pela constatação de que também ele, leitor, poderia estar a um passo de uma morte ou, a depender de sua coragem, de outra forma de vida. Esse lugar "sem saída" e ambíguo da morte, construído na linguagem, atua como vetor de uma experiência de pensamento outra, que não é acionada pela ordem da interpretação, mas pelo próprio clamor performativo da leitura. A narrativa faz morrer o jogo repetitivo de busca de aderências entre subjetividade e pensamento.

No conto "A saúde dos doentes", intensifica-se essa repetição de movimentos, culminando com o assombro de uma situação-limite. Trata-se da história de "ma- 
mãe", idosa matriarca, que, adoecendo, assiste à sua família proteger sua frágil saúde, por meio de um pacto coletivo de jogo com a verdade. A família protagoniza, cotidianamente, uma espécie de jogo cênico: para a idosa, omitem notícias sobre a morte dos parentes mortos, sobre a doença dos doentes, etc. Porém, à medida que esse engenho familiar se consolida, nessa vida fabricada por anos a fio, assustamo-nos com o desempenho de seus atores: parecem não conseguir mais viver de outro modo, que não aquele inventado em nome da saúde da matriarca. Exaustos e já quase adoecidos de tanto jogar, assistem à incansável sobrevivência da saudável doente. A matriarca, em sua última e lúcida fala no leito de morte, referindo-se a si e aos mortos, diz: "Como vocês foram bons comigo [...]. Esse trabalho todo que vocês tiveram para que eu não sofresse. Agora vocês poderão descansar [...]. Já não thes daremos mais trabalho" (Cortázar, 2009, p. 65).

Aqui, o esgotamento do limite parece ser a força que nos arrebata e impulsiona como experiência de linguagem. Progressivamente, a narrativa exacerba uma espécie de absurdo cumulativo dos gestos cotidianos, levando as situações às últimas consequências. 0 fechamento do conto projeta-nos num espaço flutuante, no qual a vida inventada se confunde com uma pretensa vida real, tornando inócua essa suposta fronteira entre realidade e fantasia e colocando em xeque o que denominamos "uma vida".

Em se tratando de experiência de pensamento, essa interrogação literária, ao acentuar o esgotamento do limite a partir da exploração do jogo de palavras anunciado - "a saúde dos doentes" - faz saltar um efeito rebote: da dobra desse esgotamento, irrompe uma estranha vitalidade.

A trama mobiliza o vício do pensar que consolida formas de vida impotentes, coletivamente partilhadas. A arrebentação desse moto contínuo acontece no gesto mesmo da escrita de Cortázar, nessa tenaz radicalização do absurdo que faz ranger os limites do possível, esgotando-o e quiçá, abrindo-o ao (im)possível.

Num jogo no qual todos se implicam, o leitor é convocado a herdar, dessas mortes, o tônus vital que pode emergir, quando um modo de pensamento/vida se esgota. Desse esgotamento do possível, o conto se transborda em intensidade.

Sós e na voragem de uma linguagem que não negocia complacências, experimentamos a vida em sua condição mais intensa: sucumbir junto com os personagens, ou lançar-se ao insuspeito, resistindo, fazendo vergar o pensamento, ávido por novos fluxos e conexões. Essa abertura ao imponderável, anunciada no modo como a própria linguagem literária conduz o arrastão, torna-se uma potência informe - eis 
o efeito vital desdobrado, quando se assume o risco de enfrentamento do horror, ou melhor, quando se afirma a coragem de levar um modo viciado de pensar ao seu limite de esgotamento.

No conto “Aí, mas onde, como”, a ultrapassagem dos limites já se efetivou, e a narrativa arma uma ambiência complexa, combinando elementos de múltiplos universos. Trata-se de um acontecimento agudo; de relato de perda afetiva; de intensidade de amizade; de permanência e convívio com o inominável. 0 escritor-personagem narra seu cotidiano perpassado por muitos mundos - sonho, memória, presente, futuro - e habitado pela incógnita "presença” de seu amigo morto, Paco, a quem interpela:

se em alguma coisa posso ajudá-lo é em saber que você não é só meu sonho, que aí, mas onde, como, que aí estás vivo e sofrendo. Desse aí não posso dizer nada, a não ser que me acontece sonhando ou acordado, que é um aí inescapável; porque quando o vejo estou dormindo e não sei pensar, e quando penso estou acordado mas só posso pensar; imagem ou ideia são sempre aquele aí, mas onde, aquele aí, mas como. (Cortázar, 2008, p.80)

A vida partilhada com o amigo insiste em permanecer convocando o mundo do presente, dilatando-o, densificando-o. A matéria do presente se faz da peculiar composição: rastros de sonhos, fragmentos de memórias, sombras de angústias e alegrias das novas implicações que esse presente dilatado pode gerar para o viver.

A narrativa parece realizar-se num espaço-tempo no qual a potência de pensamento se avoluma na medida mesma da falência das senhas orientadoras do pensar. 0 relato nos inunda de tal modo que a intensidade da relação de amizade faz ruir quaisquer esforços de acomodação do mundo a partir de conhecidas e viciadas categorias de ordenação do pensamento. Estruturas dicotômicas clássicas, tais como sonho e realidade, presente e passado, memória e imaginação, tornam-se impotentes para dar continência àquela forma de vida diferencial que força a passagem para garantir plenitude no mundo.

Essa combinação de mundos, ativada pela intensidade do afeto, por confundir e paralisar o campo de conhecimento e compreensão do personagem e do leitor, instaura outra experiência de pensamento.

Interessante destacar que a diluição do pensamento categórico ocorre, aqui, pela ativação de outra experiência com o tempo: passado, presente, futuro, sonho, vigília, 
memória e imaginário, todos se condensam num mesmo plano de vida. A disrupção do fio cronológico convoca-nos a viver, na fenda do presente, o tempo do intensivo, do acontecimento. Comentando seu trabalho, Cortázar diz:

Ter ficado imerso em outra dimensão do tempo é, para mim, uma abertura apaixonante, porque, se isso nos acontece de maneira involuntária, talvez o homem pudesse provocar esse fenômeno voluntariamente, multiplicando enormemente o tempo. (Cortázar apud Bermejo, 2002, p. 49)

Para ele, transgredir o tempo, instigando sua dilatação, parece potencializar uma experiência de pensamento. Nas três histórias, a variável do tempo atua como força diferencial de disrupção e criação. Cortázar insiste na invasão do cotidiano pelo elemento extraordinário que nele pulsa. Refratárias ao jogo do (re)conhecimento, suas narrativas nocauteiam modos de pensamento/vida e, simultaneamente, recusam o lugar de prescrição moralizante de outras formas de viver. Sua potência reside exatamente nesse vazio que se instala ao final de seu percurso, convocando o leitor a defrontar-se com seu próprio acontecer.

Isso posto, convoquemos, dessas incursões, as linhas do "fora" do debate curricular.

\section{A exterioridade Foucault-Cortázar: implicações no pensamento curricular}

Respectivamente, Foucault e Cortázar parecem convocar a exterioridade da filosofia e da literatura como atitudes urgentes de diferenciação diante dos modos de pensar que materializam as formas de vida contemporâneas.

Ambos instigam a vida à experimentação de uma condição agonística do pensar. De suas linguagens desponta que criação de pensamento se faz no duelo com linhas duras, historicamente cristalizadas. Assim, do ponto de vista dessa dobra à exterioridade do pensamento, o extraordinário, de Cortázar, parece atuar como o acontecimento, de Foucault - em ambos, a linguagem se faz arena de luta e a maquinaria do pensar, sua questão de embate.

Em Cortázar, as narrativas recusam o equilíbrio do pensável, operando um corte extraordinário no moto-contínuo do tempo presente e inventando um vazio de sentidos como lugar informe, virtualmente potente. O próprio escritor afirma: "para mim, a 
linguagem que conta é aquela que abre janelas na realidade; um ato de estar abrindo permanentemente na parede dos homens aqueles ocos que separam a gente de nós mesmos e dos demais" (Cortázar apud Bermejo, 2002, p.72).

Essa tomada de distância operada pela/na linguagem, ato radical de recusa ao (re)conhecimento de si e do mundo, parece conclamar uma forma própria de crítica do presente, acionada por um jogo literário resistente à representação.

0 descentramento de si como ultrapassagem do pensável fulgura intensa e singularmente nos autores. Foucault (2003, p. 318) é incisivo: “somos prisioneiros de algumas concepções de nós mesmos e de nossa conduta. Devemos libertar nossa subjetividade, nossa relação a nós mesmos". Movido por outros problemas de pensamento, Cortázar reverbera, quando potencializa a não subjetivação do autor e a prevalência da força da própria linguagem: “Era necessário que de algum modo o autor fizesse parte da constelação, também estivesse submetido às interações que a sua mão ia desatando ao longo do relato" (Cortázar apud Bermejo, 2002, p. 79).

Pensamento seria campo de força, efeito de linguagem e não de interioridade subjetiva. Do percurso inescapável da trama literária com seu arremesso ao inominável, criar-se-ia uma experiência outra do pensar; da coragem intensiva de uma pergunta filosófica no confronto contemporâneo com nossa condição identitária, produzir-se-ia o corte no jogo trucado do (re)conhecimento e da (re)cognição.

Os movimentos do extraordinário e do acontecimento parecem convocar exterioridades necessárias e urgentes de gestos de pensamento capazes de introduzir a diferença necessária no circuito da repetição. Tais gestos atuam como diferença na medida mesma de seu funcionamento performático, isto é, sua capacidade de incisão se faz na própria contemporaneidade agonística das relações de saber-poder. Daí o pensamento ser tomado como ato de problematização e não de reflexão ou (re)conhecimento. Daí, também, essa abordagem refutar uma análise clássica do pensamento, numa chave epistemológica ou cognitiva, e insistir numa tomada ético-política, uma vez que os alvos são os modos de governamentalização do próprio pensar.

Tais implicações tensionam o campo educacional, forçando-o a acessar sua exterioridade. Sabemos que, no contexto brasileiro, o objeto "conhecimento" tem sido alvo privilegiado nos domínios da teorização curricular, das políticas públicas e das práticas pedagógicas escolares. Estudos brasileiros alinhados a abordagens de crítica da linguagem, tais como os trabalhos de Corazza (2002); Corazza; Tadeu (2003); Silva (2002a, 2002b); Tadeu; Corazza; Zordan (2004); Veiga Neto (1995, 2003) e ou- 
tros, vêm problematizando exatamente os pilares fundacionais do sujeito, do conhecimento e da verdade, que sustentam a educação desde a modernidade.

Ao propormos, neste estudo, um deslocamento analítico - a problematização do estatuto do conhecer por meio de investigações de práticas de pensamento -, buscamos contribuir com tais vertentes críticas do debate curricular, disparando outras hipóteses de trabalho. A exterioridade Foucault-Cortázar nos interpela de tal modo, que nos demanda operar, no interior do próprio campo, o corte vertical necessário à "dobra” de nossas superfícies. Em outras palavras, trata-se de afirmar algumas linhas de força que provoquem a necessária exterioridade da pesquisa em educação diante de suas próprias práticas de pensamento.

Apontemos, pois, alguns elementos potencialmente produtivos que poderiam contribuir para um redimensionamento das problematizações, particularmente em relação às pesquisas curriculares:

a) deslocamento da questão do conhecimento para uma genealogia das práticas de pensamento: de acordo com nossa argumentação, a discussão sobre o conhecimento exige tomá-lo como efeito de práticas de pensamento. Assim, para uma análise radical das questões curriculares, interessa-nos problematizar essa naturalização da própria questão do conhecimento, seja como objeto de pesquisa curricular, de políticas curriculares ou de práticas pedagógicas. Propomos, pois, que se desloque a discussão para uma investigação genealógica das práticas de pensamento que engendram objetos de conhecimento, particularmente, no âmbito da própria pesquisa educacional, alvo deste estudo.

b) necessidade de discutir as práticas de "crítica", no crivo da problematização das práticas de pensamento: o debate curricular tem utilizado o termo "crítica" de modo hegemônico, prescindindo de seus matizes. De acordo com nossa análise, haveria distinções nessa prática. Segundo nosso estudo, seria necessário distinguir, no debate curricular, a atitude crítico-reflexiva (herdeira do pensamento moderno clássico), da atitude crítica tomada como acontecimento, como experiência diferencial do pensamento.

c) deslocamento da problematização da experiência do pensamento de um campo epistemológico e/ou cognitivo para um campo ético-político: a abordagem do problema do pensamento como uma questão de ordem epistemológica (fundada na busca das leis filosóficas do conhecer ou em teorias do conhecimento) ou psicológico-cognitiva (fundada na busca das leis gerais da cognição, da aprendizagem) prioriza a 
investigação generalizante das leis e fragiliza ou, até mesmo, suprime as discussões sobre as condições genealógicas de produção de pensamento. Em contrapartida, uma investigação acerca de práticas de pensamento articula-se necessariamente a uma atitude interrogativa ético-política, pois exige a análise das implicações entre pensamento e poder.

d) articulação entre a genealogia das práticas de pensamento e a questão do sujeito da educação: historicamente, o sujeito da educação tem sido categorizado, grosso modo, como crítico-reflexivo (a partir dos matrizes da filosofia, da sociologia e da história) ou como afetivo-cognitivo (a partir dos matrizes da psicologia, da psicanálise ou da neurociência). Tais frentes e suas variantes são referenciadas pelo sujeito da razão e ancoram-se numa abordagem reflexiva do pensar. Ao deslocarmos o campo investigativo para a genealogia das práticas de pensamento, viabiliza-se uma problematização ético-política desse "sujeito da educação", tomando-o, antes, como efeito de processos de subjetivação inextricavelmente atados às relações entre experiências de pensamento e relações de poder.

Afirmamos que o espaço analítico construído nesta pesquisa, efeito do atravessamento entre filosofia, literatura e educação, fundamenta-se na formulação foucaultiana da necessidade de liberar o pensamento de suas próprias malhas discursivas, forçando-o, por meio de um trabalho agonístico, ao encontro com sua exterioridade. Nesse sentido, discutir genealogias de práticas de pensamento no horizonte curricular impõe-se como uma urgência crítica de caráter ético-político, uma vez que a radicalidade do pensar exige o enfrentamento dos efeitos endógenos de territorialização de nossos campos de pesquisa.

Essa prática de crítica, efeito de uma economia de exterioridade entre diferentes linguagens, produz-se num jogo agonístico, cujos lances demandam uma atitude de corte vertical nessa maquinaria de pensamento representacional prevalecente em nossa contemporaneidade. Alinhada a essa forma de crítica, esta pesquisa visa reafirmar um modo ético-político de trabalho investigativo, forçando o próprio pensamento curricular a colocar-se na vertical de si mesmo, no horizonte de uma experiência da diferença. 


\section{Referências bibliográficas}

BERMEJO, Ernesto González. Conversas com Cortázar. Rio de Janeiro: Jorge Zahar, 2002. 129p.

CORAZZA, Sandra. Para uma filosofia do inferno na educação: Nietzsche, Deleuze e outros malditos afins. Autêntica: Belo Horizonte, 2002. 103p.

CORAZZA, Sandra; TADEU, Tomaz. Composições. Belo Horizonte: Autêntica, 2003. $129 \mathrm{p}$.

CORTÁZAR, Julio. Octaedro. 6. ed. Rio de Janeiro: Civilização Brasileira, 2008. 125p.

CORTÁZAR, Julio. Todos os fogos o fogo. 8. ed. Rio de Janeiro: Civilização Brasileira, 2009. 205p.

DELEUZE, Gilles. Conversações, 1972-1990. Rio de Janeiro: Editora 34, 1992. 232p.

FOUCAULT, Michel. A ética do cuidado de si como prática da liberdade. In: FOUCAULT, Michel. Ditos \& escritos V - Ética, sexualidade, política. Rio de Janeiro: Forense Universitária, 2004a. p. 264-287.

FOUCAULT, Michel. Aula de 5 de janeiro de 1983. In: FOUCAULT, Michel. O governo de si e dos outros: curso no Collège de France (1982-1983). São Paulo: WMF Martins Fontes, 2010. p. 3-39.

FOUCAULT, Michel. A verdade e as formas jurídicas. Rio de Janeiro: NAU, 1999. 158p.

FOUCAULT, Michel. Foucault estuda a razão de Estado. In: FOUCAULT, Michel. Ditos \& escritos IV - Estratégia, poder, saber. Rio de Janeiro: Forense Universitária: 2003. p. 317-322.

FOUCAULT, Michel. História da sexualidade // - O uso dos prazeres. 8. ed. Rio de Janeiro: Graal, 1998. 232p.

FOUCAULT, Michel. Nietzsche, a genealogia e a história. In: FOUCAULT, Michel. Ditos \& Escritos // - Arqueologia das ciências e história dos sistemas de pensamento. Rio de Janeiro: Forense Universitária, 2005a.

FOUCAULT, Michel. O cuidado com a verdade. In: FOUCAULT, Michel. Ditos \& escritos $V$ - Ética, sexualidade, política. Rio de Janeiro: Forense Universitária, 2004b. p. 240251.

FOUCAULT, Michel. O pensamento do exterior. In: FOUCAULT, Michel. Ditos \& escritos III - Estética: literatura e pintura, música e cinema. Rio de Janeiro: Forense Universitária, 2001. p. 219-242.

FOUCAULT, Michel. O que é a crítica? (crítica ou Aufklärung). Tradução de Antônio C. Galdino. Cadernos da F.F.C. - Faculdade de Filosofia e Ciências - UNESP, Marília, v. 9, n.1, p.169-189, 2000. 
FOUCAULT, Michel. 0 que são as Luzes? In: FOUCAULT, Michel. Ditos \& Escritos /I - Arqueologia das ciências e história dos sistemas de pensamento. Rio de Janeiro: Forense Universitária, 2005b. p. 335-351.

FOUCAULT, Michel. Theatrum Philosophicum. In: FOUCAULT, Michel. Ditos \& Escritos II - Arqueologia das ciências e história dos sistemas de pensamento. Rio de Janeiro: Forense Universitária, 2005C. p. 230-254.

LEVY, Tatiana Salem. A experiência do fora: Blanchot, Foucault e Deleuze. Rio de Janeiro: Relume Dumará, 2003.132p.

REVEL, Judith. Dicionário Foucault. Rio de Janeiro: Forense Universitária, 2011. 195p.

REVEL, Judith. O pensamento vertical: uma ética da problematização. In: GROS, F. (Org.). Foucault: a coragem da verdade. São Paulo: Parábola Editorial, 2004. p. 65-87.

SILVA, Tomaz Tadeu. Documentos de identidade: uma introdução às teorias do currículo. 2. ed. Belo Horizonte: Autêntica, 2002a. 154p.

SILVA, Tomaz Tadeu. (Org.). O sujeito da educação: estudos foucaultianos. 5. ed. Petrópolis: Vozes, 2002b. 258p.

TADEU, Tomaz; CORAZZA, Sandra; ZORDAN, Paula. Linhas de escrita. Belo Horizonte: Autêntica, 2004. 205p.

VEIGA NETO, Alfredo (Org.). Crítica pós estruturalista e educação. Porto Alegre: Sulina, 1995. 26op.

VEIGA NETO, Alfredo. Foucault e a Educação. Belo Horizonte: Autêntica, 2003. 191p.

Submetido à publicação em 14 de novembro de 2012. Aprovado em 10 de abril de 2013. 
238 